\section{Postmyocardial infarction education is effective but not enough on its own}

\author{
Rod Taylor
}

Giannopoulos et $a l^{1}$ report that delivering a stand-alone educational programme following myocardial infraction (MI) reduces the risk of cardiovascular events. This single-centre trial, based in a university hospital in Athens, randomised 329 postmyocardial patients to either an 8 -week programme of structured education plus usual care (intervention) or usual care (control). The authors reported that the intervention consisted of 10 hours of contact on risk factor management, lifestyle and drugs, delivered by a nonhealthcare personnel with interactive patient sessions, aimed at enhancing patient adherence to lifestyle change and treatment compliance. At a mean follow-up of 17 months, the authors reported an HR for the primary composite outcome (all-cause death, MI, stroke and hospitalisation) of 0.48 (95\% CI 0.32 to 0.73 ) and major adverse cardiovascular and cerebrovascular event of 0.49 (0.27 to 0.28 ). With similar mortality in both groups, improvements were driven by reduced rates non-fatal events in intervention compared with control: MI (13 vs 22), stroke (2 vs 7) and cardiovascular hospitalisation (14 vs 22).

What is the mechanistic basis of this improvement in non-fatal events? As noted by the authors, an improvement in risk factors is likely to be a key explanation. Greater changes from baseline at 12 months in the education group compared with controls were seen in low density lipoprotein cholesterol (median change: -53.5 vs $-35.0 \mathrm{mg} / \mathrm{dL}$ ), systolic blood pressure $(-8.0$ vs $-2.0 \mathrm{~mm} \mathrm{Hg}$ ) and body mass index (0 vs $2.0 \mathrm{~kg} / \mathrm{m}^{2}$, $\mathrm{p}<0.001)$. Intriguingly, no difference in adherence to medication (including use of statins and antihypertensives) over the duration of the study or between the two groups was seen, indicating that that risk factor improvement (and consequent reduction in the risk of events) was the result of changes in lifestyle behaviour following participation education intervention. As behavioural outcomes such

MRC/CSO Social and Public Health Sciences Unit \& Robertson Centre for Biostatistics, Institute of Health and Well Being, University of Glasgow, Glasgow, UK

Correspondence to Professor Rod Taylor, University of Exeter, Exeter, UK; Rod.Taylor@glasgow.ac.uk as diet and physical activity were not reported, that the mechanistic basis of the education intervention was improved lifestyle remain a hypothesis.

In contrast to the Giannopoulos trial, the meta-analysis of the Cochrane review of randomised controlled trials published in 2017 showed there to is no strong evidence that participation in educational interventions improved either all-cause mortality (relative risk (RR) $0.80,95 \% \mathrm{CI}$ 0.60 to 1.05 ) or cardiovascular events (fatal and/or non-fatal MI: RR 0.63, 0.26 to 1.48 ; coronary artery bypass graft and percutaneous coronary intervention: RR $0.58,0.19$ to 1.71 ; hospitalisations: RR $0.93,0.71$ to 1.21 ) for people with coronary heart disease ${ }^{2}$. Although based on sizeable literature, that is, 22 trials in 76864 participants, the Cochrane team identified several limitations in the included evidence base. The case mix of participants recruited to trials varied considerably: MI, postrevascularisation and stable angina with a wide range of disease severity and timings from diagnosis or event. There was substantial variation in the nature and dose of interventions employed by trials, ranging from one trial that employed a single $40 \mathrm{~min}$ face-to-face teaching session plus a $15 \mathrm{~min}$ follow-up phone call to a 4-week residential stay followed by 11 months of regular nurse-led follow-up sessions. Because of poor reporting of trials methods, there was considerable uncertainty in trial methodological quality. Given these limitations, the Cochrane authors called for: '... further definitive research into education interventions for people with CHD...'. Giannopoulos et al respond to this call with a trial that: (1) targets a defined homogenous population of MI patients, (2) provides a transparent report of study methods, including description of generation of the randomisation sequence, and (3) reports a primary outcome assessed by blinded event adjudication.

To fully understand the applicability of the Giannopoulos trial, it is important that we view its educational programme through the lens of a 'complex intervention', that is, as an intervention whose efficacy/effectiveness depends on number of interacting factors: the theoretical basis for the intervention, the context and method of intervention delivery and how recipients respond to receivership of the intervention (eg, changes in health behaviour). ${ }^{3}$ Reporting frameworks have been developed for complex intervention trial authors to supplement the core Consolidated Standards of Reporting Trials requirements for randomised controlled trials. ${ }^{4}$ Additional reporting items include the intervention underlying theoretical basis (how will the intervention cause change?), method of intervention development (eg, were patients, clinicians and other key stakeholders involved in the intervention design?), fidelity of delivery (eg, what checks were in place in the trial to check that the intervention was delivered as planned?) and the costs and resources (eg, staffing) to deliver of the intervention. That such details were not available limits our ability to judge the applicability of this educational intervention to the UK National Health Service or other healthcare settings.

So, how should the Giannopoulos trial in inform our clinical practice? While a positive study, the addition of the outcome findings of this trial does not overturn the 'neutral' meta-analysis findings of the Cochrane review above. It would therefore seem appropriate that we continue to follow the clinical practice conclusions of the Cochrane authors and recommend educational interventions as part of a wider comprehensive programme of rehabilitation that also includes exercise and psychological support, consistent with national guidance for the management of people with MI. ${ }^{67}$

Contributors RT conceived and wrote this editorial.

Funding The authors have not declared a specific grant for this research from any funding agency in the public, commercial or not-for-profit sectors.

Competing interests None declared.

Patient and public involvement Patients and/ or the public were not involved in the design, or conduct, or reporting, or dissemination plans of this research.

Patient consent for publication Not required.

Provenance and peer review Commissioned; externally peer reviewed.

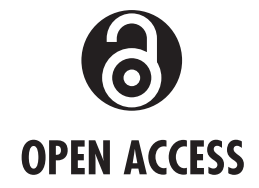

Open access This is an open access article distributed in accordance with the Creative Commons Attribution Non Commercial (CC BY-NC 4.0) license, which permits others to distribute, remix, adapt, build upon this work non-commercially, and license their derivative works on different terms, provided the original work is properly cited, appropriate credit is given, any changes made indicated, and the use is 
non-commercial. See: http://creativecommons.org/ licenses/by-nc/4.0/.

(c) Author(s) (or their employer(s)) 2021. Re-use permitted under CC BY-NC. No commercial re-use. See rights and permissions. Published by BMJ.

\section{D) Check for updates}

To cite Taylor R. Heart 2021;107:1026-1027.

Published Online First 13 May 2021

\section{S Linked}

http://dx.doi.org/10.1136/heartjnl-2020-318414

Heart 2021;107:1026-1027. doi:10.1136/heartjnl-2020-318850

\section{ORCID iD}

Rod Taylor http://orcid.org/0000-0002-3043-6011

\section{REFERENCES}

1 Giannopoulos G, Karageorgiou S, Vrachatis D, et al. A stand-alone structured educational programme after myocardial infarction: a randomised study. Heart 2021;107:1047-53.

2 Anderson L, Brown JP, Clark AM, et al. Patient education in the management of coronary heart disease. Cochrane Database Syst Rev 2017;6:CD008895.

3 Shahsavari H, Matourypour P, Ghiyasvandian S, et al. Medical Research Council framework for development and evaluation of complex interventions: a comprehensive guidance. J Educ Health Promot 2020;9:88
4 Moher D, Schulz KF, Altman DG. The CONSORT statement: revised recommendations for improving the quality of reports of parallel-group randomised trials. Lancet 2001;357:1191-4.

5 Möhler R, Köpke S, Meyer G. Criteria for reporting the development and evaluation of complex interventions in healthcare: revised guideline (CReDECI 2). Trials 2015:16:204

6 National Institute for Care Excellence (NICE). Acute coronary syndromes. Guideline [NG185] Published date: 18 November 2020, London. Available: https://www. nice.org.uk/guidance/ng185

7 British association for cardiovascular prevention and rehabilitation (BACPR) 2017 standards and core components for cardiovascular disease prevention and rehabilitation. Available: https:// www.bacpr.com/resources/BACPR_Standards_and_ Core_Components_2017.pdf 